J. S. Volek

\title{
To: McAuley KA, Hopkins CM, Smith KJ, McLay RT, Williams SM, Taylor RW, Mann JI (2005) Comparison of high-fat and high-protein diets with a high-carbohydrate diet in insulin-resistant obese women. Diabetologia 48: 8-16
}

Published online: 3 June 2005

(C) Springer-Verlag 2005

To the Editor: I compliment McAuley et al [1] on their recently published work comparing various popular diet approaches that differ in macronutrient distribution. I found it quite surprising, however, that the authors were not more enthusiastic about finding a differential weight loss value among diets of equal energy content. Consistent with other recently reported findings (reviewed in [2]), there was a greater weight loss in subjects consuming the very-low-carbohydrate (Atkins) diet $(-7.1 \mathrm{~kg})$ compared with the conventional low-fat diet $(-4.3 \mathrm{~kg})$. McAuley et al [1] downplay the results of their study and appear to believe that the difference is attributable to under-reporting of food consumed and greater fluid loss in the low-carbohydrate group. Although under-reporting on weight loss diets has been known to happen [3], without experimental evidence there is no reason to believe that, in this and other studies, underreporting occurred only in subjects randomised to the lowcarbohydrate diet. The idea that greater fluid loss would account for differences in weight loss over a 24 -week period is also improbable, since the authors present no experimental evidence of dehydration.

Body composition assessed by bioelectrical impedance showed a significantly greater fat loss in the very-low-carbohydrate group $(-5.2 \mathrm{~kg})$ compared with in the low-fat group $(-3.9 \mathrm{~kg})$. It thus seems that the most important result from this study was that the absolute fat loss was greater on the low-carbohydrate diet, a finding consistent with other studies that used a more precise method of measuring body composition, dual-energy X-ray absorptiometry $[4,5]$. The greater absolute loss of fat on very-low-carbohydrate diets has major clinical significance, especially considering that

J. S. Volek $(\bowtie)$

Department of Kinesiology, University of Connecticut,

2095 Hillside Road, Unit 1110

Storrs, CT, 06269-1110, USA

e-mail: jeff.volek@uconn.edu

Tel.: +1-860-4866712

Fax: +1-860-4861123 fat may be preferentially mobilised from the trunk [5], a region associated with insulin resistance, diabetes, dyslipidaemias and atherosclerosis.

Certainly, any study that finds a greater weight loss with one particular diet should be viewed as important. A diet that also enhances fat loss should be considered of major clinical impact. Any such findings should be carefully compared with those of other similar studies and discussed in terms of theoretical mechanisms [6, 7]. In this context, I feel that McAuley et al demonstrated a certain bias against low-carbohydrate diets. Considering the other favourable outcomes of the low-carbohydrate diet compared with the low-fat group (improved triglycerides, glucose, insulin, Creactive protein, HDL, etc.), and the consistency of these findings with many other studies, the authors might consider a more dispassionate discussion of their results.

\section{References}

1. McAuley KA, Hopkins CM, Smith KJ et al (2005) Comparison of high-fat and high-protein diets with a high-carbohydrate diet in insulin-resistant obese women. Diabetologia 48:8-16

2. Westman EC, Mavropoulos J, Yancy WS, Volek JS (2003) A review of low-carbohydrate ketogenic diets. Curr Atheroscler Rep 5:476-483

3. Lichtman SW, Pisarska K, Berman ER et al (1992) Discrepancy between self-reported and actual caloric intake and exercise in obese subjects. N Engl J Med 327:1893-1898

4. Brehm BJ, Spang SE, Lattin BL, Seeley RJ, Daniels SR, D'Alessio DA (2004) The role of energy expenditure in the differential weight loss in obese women on low-fat and lowcarbohydrate diets. J Clin Endocrinol Metab 90:1475-1482

5. Volek JS, Sharman MJ, Gomez AL et al (2004) Comparison of energy-restricted very low-carbohydrate and low-fat diets on weight loss and body composition in overweight men and women. Nutr Metab (Lond) 1:13

6. Feinman RD, Fine EJ (2004) "A calorie is a calorie" violates the second law of thermodynamics. Nutr J 3:9

7. Feinman RD, Fine EJ (2003) Thermodynamics and metabolic advantage of reducing diets. Metab Syndr Rel Disord 1:209 219 